\title{
The Alberta Heart Failure Etiology and Analysis Research Team (HEART) study
}

Justin A Ezekowitz ${ }^{1,4^{*}}$, Harald Becher ${ }^{1,4}$, Israel Belenkie ${ }^{2,3}$, Alexander M Clark ${ }^{1,6}$, Henry J Duff ${ }^{2,3}$, Matthias G Friedrich ${ }^{3,7,8}$, Mark J Haykowsky ${ }^{1,9}$, Jonathan G Howlett ${ }^{2,3}$, Zamaneh Kassiri ${ }^{1,10}$, Padma Kaul ${ }^{4}$, Daniel H Kim ${ }^{1,4}$, Merril L Knudtson 2,3, Peter E Light ${ }^{1,11,12}$, Gary D Lopaschuk ${ }^{1,5}$, Finlay A McAlister ${ }^{1,4}$, Michelle L Noga ${ }^{1,13}$, Gavin Y Oudit ${ }^{1,4}$, D lan Paterson 1,4, Hude Quan ${ }^{2,3}$, Richard Schulz ${ }^{1,5,12}$, Richard B Thompson ${ }^{1,14}$, Sarah G Weeks ${ }^{2,3}$, Todd J Anderson ${ }^{2,3}$ and Jason RB Dyck ${ }^{1,5}$

\begin{abstract}
Background: Nationally, symptomatic heart failure affects $1.5-2 \%$ of Canadians, incurs $\$ 3$ billion in hospital costs annually and the global burden is expected to double in the next 1-2 decades. The current one-year mortality rate after diagnosis of heart failure remains high at $>25 \%$. Consequently, new therapeutic strategies need to be developed for this debilitating condition.

Methods/Design: The objective of the Alberta HEART program (http://albertaheartresearch.ca) is to develop novel diagnostic, therapeutic and prognostic approaches to patients with heart failure with preserved ejection fraction. We hypothesize that novel imaging techniques and biomarkers will aid in describing heart failure with preserved ejection fraction. Furthermore, the development of new diagnostic criteria will allow us to: 1) better define risk factors associated with heart failure with preserved ejection fraction; 2) elucidate clinical, cellular and molecular mechanisms involved with the development and progression of heart failure with preserved ejection fraction; 3 ) design and test new therapeutic strategies for patients with heart failure with preserved ejection fraction. Additionally, Alberta HEART provides training and education for enhancing translational medicine, knowledge translation and clinical practice in heart failure. This is a prospective observational cohort study of patients with, or at risk for, heart failure. Patients will have sequential testing including quality of life and clinical outcomes over 12 months. After that time, study participants will be passively followed via linkage to external administrative databases. Clinical outcomes of interest include death, hospitalization, emergency department visits, physician resource use and/or heart transplant. Patients will be followed for a total of 5 years.
\end{abstract}

Discussion: Alberta HEART has the primary objective to define new diagnostic criteria for patients with heart failure with preserved ejection fraction. New criteria will allow for targeted therapies, diagnostic tests and further understanding of the patients, both at-risk for and with heart failure.

Trial registration: ClinicalTrials.gov NCT02052804.

Keywords: Heart failure, Preserved ejection fraction, Heart failure risk factors, Heart failure diagnosis

\footnotetext{
* Correspondence: jae2@ualberta.ca

${ }^{1}$ Mazankowski Alberta Heart Institute, 2C2 WMC, 8440-112 Street, Edmonton,

AB, Canada

${ }^{4}$ Department of Medicine, University of Alberta, Edmonton, $A B$, Canada

Full list of author information is available at the end of the article
} 


\section{Background}

Cardiovascular disease is one of the primary causes of death and disability in Canada and is a leading cause of death worldwide (http://www.who.int/chp/chronic_disease_report/en/). While advancements in medical and surgical therapies have improved cardiac mortality, these advances have led to an increase in the incidence and prevalence of heart failure (HF) [1]. At the national level, symptomatic HF affects $1.5-2 \%$ of Canadians, incurs $\$ 3$ billion in hospital costs annually, and the global burden is expected to double in the next 1-2 decades [2,3]. In addition, the current one-year mortality rate after diagnosis of HF remains disturbingly high at $>25 \%[4,5]$, and the condition has the worst effect on quality of life of any chronic medical condition [6]. Consequently, new therapeutic strategies need to be developed for this debilitating condition.

HF is a clinical syndrome characterized by specific symptoms (e.g. shortness of breath and reduced exercise capacity) as well as physical examination findings. HF has traditionally been described by a depressed ejection fractions ranging from $<30-45 \%$ with $<40 \%$ used as a criteria that is generally used in clinical trials and guidelines [7-9]. However, up to $50 \%$ of patients presenting with HF have preserved systolic function and are thus diagnosed with "diastolic HF" $[3,10,11]$. It is now recognized that a diverse group of cardiac diseases give rise to this condition and thus the clinical and research community has more appropriately renamed "diastolic HF" as HF with a preserved ejection fraction (HF-PEF) or HF-preserved systolic function (HF-PSF). Regardless of the nomenclature, no therapy has been proven in randomized clinical trials to reduce the morbidity or mortality of HF-PEF and, as such, no guideline endorses a specific therapy targeted at HF-PEF $[8,9,12,13]$. While the lack of an available agent is multi-factorial, we believe that the current criteria used for defining HF-PEF are inadequate. This may skew patient stratification in HF trials and prevent the identification of therapies that may actually have benefit in HF-PEF.

The objective of the Alberta HEART program (http:// albertaheartresearch.ca) is to develop novel diagnostic, therapeutic and prognostic approaches to patients with HF-PEF. We hypothesize that novel imaging techniques and biomarkers will aid in describing HF-PEF. Furthermore, the development of new diagnostic criteria will allow us to: 1) better define the risk factors associated with the HF-PEF; 2) elucidate the clinical, cellular and molecular mechanisms involved with the development and progression of HF-PEF; 3) design and test new therapeutic strategies for patients with HF-PEF. Alberta HEART additionally provides training and education program for enhancing translational medicine, knowledge translation and clinical practice in heart failure.

\section{Methods/design}

Trial status

The study is approved by the Health Research Ethics Boards at the University of Alberta, Covenant Health and the University of Calgary. Recruitment began in January 2010 and as of March 31, 2014, 649 patients have been enrolled. ClinicalTrials.gov NCT02052804.

\section{Study design}

This is a prospective observational cohort study of patients with, or at risk for, HF.

\section{Study population}

Patients are adults (i.e. aged over 18 years of age) recruited from Alberta (population 4.0 million), principally in Edmonton and Calgary but also from rural regions. In order to enroll and study patients across the spectrum of risk of developing HF, with signs or symptoms mimicking HF, or with a diagnosis of HF, a broad recruitment strategy that categorizes patients into 5 distinct groups is underway. The 5 distinct groups are:

1. High-risk of developing HF-PEF but no clinically overt HF: Patients will have one or more of the following: hypertension ( $\geq 3$ medications or LVH on ECG or left ventricular mass index $>$ gender-matched upper limit normal on an imaging test); diabetes ( $>45$ years of age); atrial fibrillation; or obesity (body mass index $>30)$. Patients will be generally asymptomatic (no dyspnea or fatigue) and have no known prior $\mathrm{HF}$ or other cardiovascular disease.

2. High-risk of developing HF-PEF with other clinically overt disease: Patients with other cardiovascular diseases will be recruited including atrial fibrillation, chronic coronary artery disease (including those with a recent acute coronary syndrome $>2$ weeks prior), and COPD.

3. Patients with known HF-PEF: These are patients who have been diagnosed with HF-PEF based on the clinical phenotype of symptoms consistent with HF, and a preserved ejection fraction. Patients with the clinical diagnosis of HF-PEF and an ejection fraction $>45 \%$ will be enrolled in this study from the heart failure clinics in Alberta. For further definition, the group will be divided into $3 a$ (LVEF always $\geq 45 \%$; no right ventricle involvement), $3 \mathrm{~b}$ (LVEF previously $<45 \%$, now $\geq 45 \%$; with or without right ventricle involvement), and 3c (LVEF always $\geq 45 \%$; right ventricle involvement or pulmonary hypertension (TAPSE <16 mm, PASP > $35 \mathrm{mmHg}$, or clinical judgment)).

4. Patients with known systolic HF: Patients with systolic HF often have abnormalities in the mechanical diastolic function and are necessary to 
complete the spectrum to act as a comparator for group 3. An ejection fraction $<45 \%$ and a diagnosis of HF will be included.

5. Healthy age- and gender-matched controls: Patients with no evidence of coronary artery disease, hypertension, diabetes mellitus, organ disease or replacement therapies; no evidence of inflammatory or autoimmune conditions and not on cardiac medications.

Patients will be recruited from HF and other clinics across Alberta. Control patients are recruited through referrals from patients, clinicians and the broader community across Alberta via public advertising, media events and other public engagement. All patients signed informed consent and the study is approved by the Health Research Ethics Boards at the University of Alberta, Covenant Health and the University of Calgary. After consent, patients are enrolled and undergo comprehensive clinical, quality of life, biomarker, electrophysiologic and imaging assessments (Figure 1). Patients are also eligible for substudy enrollment (see below). Patients are re-assessed at 6 and 12 months and longer-term clinical and outcome surveillance is planned. Data is managed on the Alberta Provincial Project for Outcome Assessment in Coronary Heart Disease platform (http://www.approach.org/).

\section{Adjudication}

Given the lack of a single accepted and validated definition for HF-PEF, the 3 most commonly used clinical criteria from landmark papers [14-16] ongoing or completed trials $[17,18]$ or population studies $[3,10,11]$ will be evaluated for applicability to the development of new criteria (Table 1). These criteria highlight two important points:
(1) diagnostic uncertainty may exist and should be captured by any criteria proposed using a hierarchical methodology; and (2) time of evaluation may alter the certainty of the diagnosis as clinical findings (and non-invasive or invasive markers) may change with therapy or time. In addition, none of these 3 sets of criteria have been compared, or evaluated in the setting of other conditions, which may mimic symptoms of HF (e.g. lung disease, hypertension, diabetes, obesity, deconditioning).

Each of the three definitions will be applied to the cohort in order to evaluate the sensitivity, specificity, diagnostic accuracy, positive predictive value and negative predictive value using the diagnostic testing model based on Bossuyt et al. [20] and Sackett and Haynes [21] and the reporting methods endorsed by STARD [22] and QUADAS-2 [23]. A reference standard for HF-PEF is currently absent. Therefore, we have chosen to use a consensus panel approach using a panel of adjudicators blinded to the group of original recruitment (Figure 2).

\section{Phase 1}

In the first phase, the adjudicators will be asked to group the participants into one of the 5 groups above, using pre-enrollment (i.e. no study related variables) clinical criteria. We will then test the current definitions as to their validity.

\section{Phase 2}

In the second phase, information from the study echocardiogram and cardiac MRI will be used to readjudicate participants and explore if the clinical phenotype can be better enhanced using standardized imaging biomarker information.

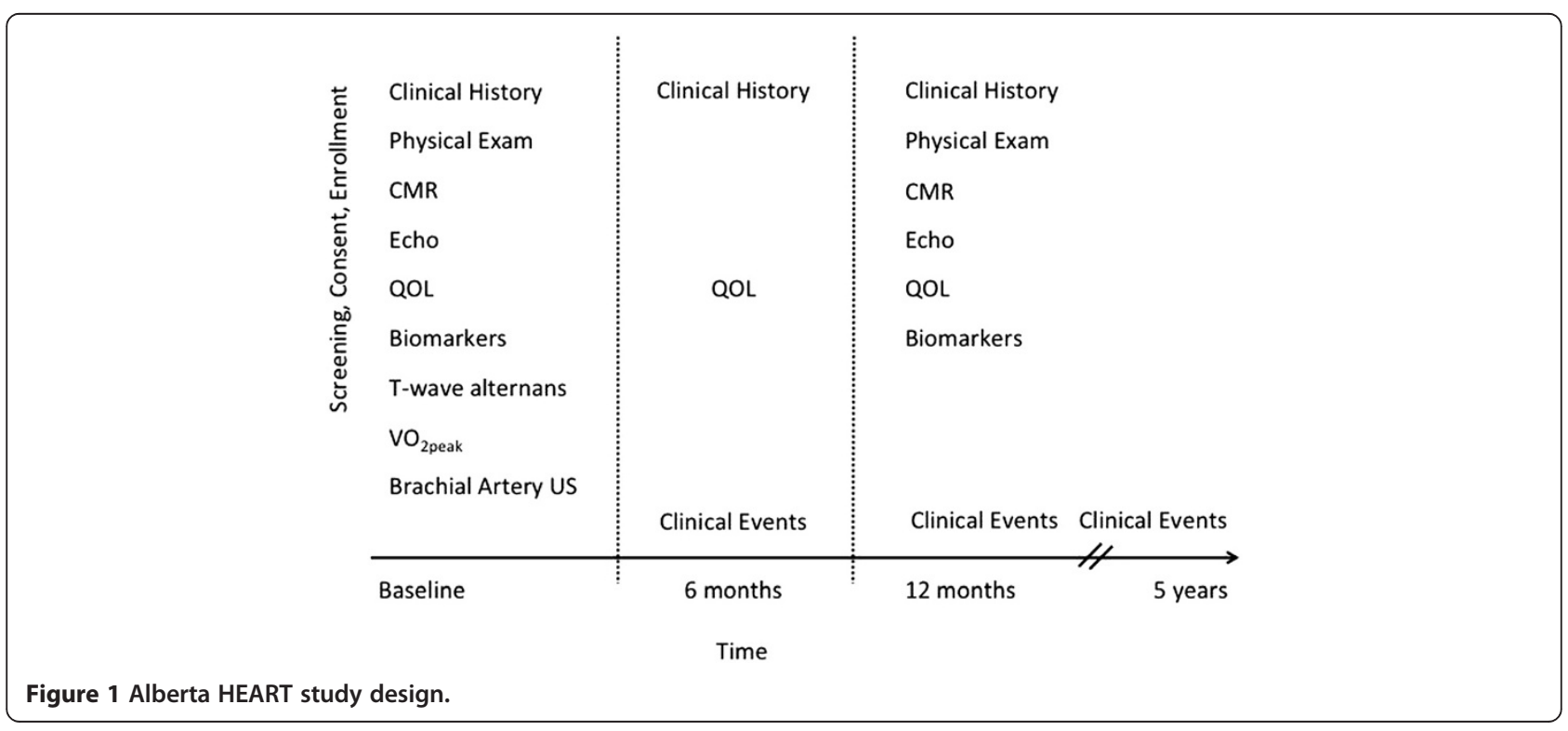


Table 1 Current diagnostic criteria for HF-PEF

\begin{tabular}{|c|c|c|c|}
\hline Definition & $\operatorname{ESC}[12,14]$ & Vasan et al. [15] & Zile et al. $[16,19]$ \\
\hline Signs or symptoms? & Symptoms and signs of HF & $\begin{array}{l}\text { Symptoms and signs, supporting laboratory tests } \\
\text { and a typical clinical response to treatment }{ }^{\#}\end{array}$ & $\begin{array}{l}\text { Symptoms and signs of HF } \\
\text { (by Framingham criteria) }\end{array}$ \\
\hline Ejection fraction & LVEF $>50 \%$ and LVEDVI $<97 \mathrm{mls} / \mathrm{m}^{2}$ & LVEF $\geq 50 \%$ within 72 hours of HF event** & LVEF $>50 \%$ \\
\hline \multirow{2}{*}{$\begin{array}{l}\text { Echo/Cath/Biomarker evidence } \\
\text { of diastolic dysfunction? }\end{array}$} & \multirow[t]{2}{*}{ Yes } & Yes s** $^{* *}$ & \multirow[t]{2}{*}{ Not required } \\
\hline & & $\begin{array}{l}\text { Abnormal LV relaxation, filling, distensibility } \\
\text { indices on cardiac catheterization }\end{array}$ & \\
\hline
\end{tabular}

\#with diuretics, with or without documentation of elevated LV filling pressure (at rest, on exercise, or in response to a volume load) or a low cardiac index;

${ }^{* *}$ downgraded to "Probable" if EF not defined in first 72 hours; ***downgraded to "Possible" if no Echo or Cath evidence; ESC, European Society of Cardiology.

\section{Phase 3}

In the third phase, data from the clinical phenotype, novel imaging markers, and biomarker testing to see if it can identify distinct patient cohorts. This will also incorporate novel imaging or biomarkers that are emerging or have not been previously validated.

\section{Phase 4}

In the final phase, all of the above will be integrated to develop a de novo diagnostic system via a panel-based method. Potential criteria will be viewed singly and together in order to develop a novel diagnostic scoring system with the following principles: (1) clinical symptoms and signs must be included as a basis for the diagnosis of HF-PEF; (2) diagnostic certainty should be categorized into definite, probable, possible, and not present; (3) time of evaluation must be included with respect to acute events; (4) no binary LVEF cutoff exists therefore a spectrum of LVEF will be used; (5) areas to be considered as candidate variables for evaluation should include mechanical, electrical, biomarker, and imaging modalities and should be done at rest and with provocation of exercise; (6) subtypes of HF-PEF likely exist based on etiology or mechanism of dysfunction and these subtypes likely include, but are not limited to, ventricular- vascular decoupling, myocyte dysfunction, infiltration, valverelated, extracellular matrix hypertrophy, post-operative and arrhythmia-related, especially atrial fibrillation; and (7) a simple clinical tool will be adopted if valid and clinically relevant, so attention to the end-user will be incorporated at an early stage through interaction with end-users (see www.albertaheartresearch.ca). External validation will be sought in existing datasets including MAGGIC, CHARM and the Olmsted County database.

\section{Imaging- MRI and echocardiography}

Most diagnostic constructs for the identification of HF-PEF, such as those from the European Society of Cardiology (Table 1) [14], employ imaging-measures of diastolic function in a diagnostic algorithm. However, these are used as binary variables and cut-points considered important for the diagnosis of HF-PEF. Several new quantitative imaging tests are available that more directly measure the physical mechanisms during ventricular relaxation that are associated with diastolic function, such as ventricular untwisting and global tissue strain rates, or that reflect tissue characteristics including diffuse and focal fibrosis and edema.

Thus, our goal is to evaluate a wider array of imaging tests for the purpose of defining a new set of practical criteria for the characterization of diastolic dysfunction 
that would be widely available. In addition to standard measures, main features will be evaluated using one or both of echocardiographic and CMR imaging: (1) ventricular stiffness [24,25]; (2) ventricular relaxation [24,26]; and (3) ventricular-vascular coupling [27,28]. This new approach will address the significant variability (often due to load dependence) and low specificity of the conventional imaging parameters of diastolic function and develop load-independent measures.

In brief, the CMR scans will be performed on a $1.5 \mathrm{~T}$ magnet (Sonata, Siemens and Avanto, Siemens) and will include an assessment of: (1) atrial and ventricular volumes and function using steady state free precession (SSFP), (2) myocardial tissue characterization using late gadolinium enhancement (LGE) as well as quantitative T1 and T2 imaging, (3) estimation of ventricular and vascular stiffness using SSFP, phase contrast and tagging techniques and (4) pulmonary water content. For LGE and T1 imaging, $0.15 \mathrm{mmol} / \mathrm{kg}$ of gadolinium contrast (Gadovist, Bayer) will be given intravenously. Cardiac volumes and function and myocardial scar will be analyzed using commercially available software (Syngo, Siemens and CMR42, Circle) by experienced interpreters blinded to the study group assignment. Other measures of cardiac function and myocardial tissue characterization as well as vascular function and pulmonary water content will be performed using custom built software (MATLAB).

2D and 3D echocardiography will be performed on IE 33 (Philips) scanners with and without intravenous injection of the ultrasound contrast agent Definity. In addition, recordings using color, spectral, tissue Doppler and speckle tracking imaging will be obtained according to the American Society of Echocardiography (ASE). The following measurements will be performed by two experienced observers according ASE standards: LV volumes, ejection fraction, LA volumes, RV size and function, quantification of valvular lesions, systolic pulmonary artery pressure, mitral/tricuspid inflow velocities, mitral/tricuspid annular velocities, global longitudinal strain and strain rate. The recordings will also be processed using custom built software for fusion of 3D datasets and new tools to assess myocardial deformation which promise a more reliable assessment of volume changes as well as systolic and diastolic LV/RV function.

\section{Exercise physiology substudy}

A cardinal feature of HF, even when well compensated, is decreased exercise capacity $\left(\mathrm{VO}_{2 \text { peak }}\right)$ that is due, in part, to impaired cardiovascular and skeletal muscle that results in reduced convective or diffusive $\mathrm{O}_{2}$ transport or decreased $\mathrm{O}_{2}$ utilization by the active muscles [29,30]. Currently, no study has prospectively examined the determinants of exercise intolerance across the HF continuum (i.e. healthy individuals and AHA/ACC stages A to C), therefore, uncertainty remains regarding the role that abnormal cardiac, vascular or skeletal muscle function play in limiting peak $\mathrm{VO}_{2}$ across the health, at risk and HF continuum.

The goal of the substudy is to compare peak $\mathrm{VO}_{2}$ (and its determinants) in healthy individuals, individuals at risk for HF and clinically stable individuals with HF-REF and HF-PEF. Subjects will be drawn from Groups 1 to 5 (above) and will undergo a cardiopulmonary exercise test on a Lode (Groningen, NL) cycle ergometer (resting, with $15 \mathrm{~W}$ increase in peak power output every two minutes until volitional exhaustion) with expired gas analysis and inert gas rebreathing (Innocor CPX, Odense, DK) [31] to measure peak $\mathrm{VO}_{2}$ and its Fick determinants (i.e. peak heart rate, stroke volume, cardiac output, systemic vascular resistance, arterial-venous oxygen difference). We will also use a non-invasive multisensory accelerometer (SenseWear Armband) to measure Daily Energy Expenditure (DEE), which will provide information on how physical activity measurements relate to established prognostic parameters. Assessing physical activity in patients doing their usual activities allows for day-to-day fluctuations to be taken into account. This will objectively assess daily physical activity, sedentary time and energy expenditure and compare these measures to established HF prognostic parameters.

In addition, the role that vascular function (MRI-derived aortic distensibility, brachial artery flow mediated dilation) and ventricular-arterial coupling abnormalities may play in limiting exercise performance will also be determined.

\section{Vascular substudy}

The endothelium plays a key role in vascular homeostasis through the release of a variety of autocrine and paracrine substances [32,33]. Dysfunction of endothelial cells is a systemic process and the initiating event in atherosclerosis. This has adverse effects on afterload and ventricular-vascular mismatch may occur. Over the past two decades it has been clearly demonstrated that subjects with systolic dysfunction have impairment of endothelial function. It was recently demonstrated that subjects with HF-PEF did not have attenuated conduit vessel endothelial dysfunction compared with age-matched controls [34]. Exercise training in this group improved $\mathrm{VO}_{2 \max }$ but not large vessel endothelial function [35]. However, another group demonstrated attenuation of microvascular function in a cohort with HF-PEF and was able to demonstrate an association of microvascular function with outcomes [36]. We will recruit: (a) control subjects with no signs or symptoms of HF; (b) subjects with HF and systolic dysfunction due to dilated cardiomyopathy ( $\mathrm{EF}<35 \%$ and no coronary artery disease) and no active vascular risk factors; and (c) subjects with HF-PEF in Group 3 (above) and no active vascular risk factors. Subjects will undergo the 
following non-invasive assessments of vascular health: a) brachial flow-mediated dilation, b) hyperaemic velocity, and c) finger-tip pulse arterial tonometry (PAT). These measure conduit vessel endothelial function (FMD), microvascular function (hyperaemic velocity), fingertip small vessel endothelial function and capacitance (PAT). Details of the methodology are well published and utilized by our group $[37,38]$.

\section{Blood pressure wave substudy}

Cardiac catheterization is indicated for clinical reasons in a subset of patients enrolled into Alberta HEART. These patients will undergo an additional set of high fidelity simultaneous pressure and flow measurements using a combined Doppler/Millar pressure wire (Combiwire ${ }^{\oplus}$ Seimens) at 5 pre-specified locations in the aorta (vena contracta, midaortic arch, distal to left subclavian, at the diaphragm and infrarenal). Using this data, we will validate the ReservoirPressure theory of pressure/flow propagation in humans (already validated in large animal models). The successful validation of this approach will enable us to predict, using a derived mathematical formula, the effects of antihypertensive agents (both existing and new) as well as future device interventions upon individual pressure dynamics. We also hope to determine characteristics of the pressure/volume wave to potentially predict the development of future vascular de-coupling and/or ventricular remodeling.

\section{Biomarkers substudy}

The use of biomarkers will allow us to screen high-risk populations, to create a risk-prediction model in patients with HF-PEF and to provide new insights into the pathophysiology of HF-PEF. We hope to distinguish between HF-PEF and HF-REF and to provide prognostic insight into those with overt disease with the ultimate aim of providing tailored therapy to these different patient populations $[39,40]$. Importantly, we will be able to link these data to important clinical outcomes such as mortality, survival free of heart transplantation, and hospitalizations. These biomarkers will also be linked with our findings from vascular physiology and imaging assessment. Serum, plasma samples and whole blood will be collected and stored for analysis in our core biomarker facilities. Biomarker testing will encompass both hypothesis-generating and hypothesis-testing approaches. An "omics" platform will be used, including microarray (mRNA and microRNA), proteomics and metabolomics with a systems-based analysis. A more tailored biomarker analysis of the extracellular matrix, natriuretic peptides, inflammatory biomarkers and other novel biomarkers will also be undertaken. We will collaborate with the Prevention of Organ Failure Centre of Excellence (PROOF; www.proofcentre.ca) at the University of British Columbia, which is cross-disciplinary team that unites scientific, technical, and commercialization expertise in order to implement biomarkers to improve management of heart, lung and kidney disease.

\section{Risk substudy}

Patients will undergo non-invasive risk evaluation using locally developed technology [41]. The technology is the antithesis of a Holter monitor, as instead of randomly acquiring data, signals are obtained during scripted interventions designed to elicit physiologic transients, which unmask physiologic defects in auto-regulation. Using this data acquisition system, 2 metrics of risk of death were discovered and partially validated. In contrast to the current study, the original pilot study only recorded a single bipolar ECG whereas we now record 6 standard ECG leads. This will provide a better opportunity to examine spatial heterogeneity of $\mathrm{T}$ wave alternans.

\section{Clinical outcomes}

Patients will have sequential testing including quality of life and clinical outcomes over the first 12 months of study entry. After that time, we will passively follow study participants via linkage to external administrative databases held by Alberta Health. Clinical outcomes of interest include death, hospitalization, emergency department visits, physician resource use, and/or heart transplant. Patients will be followed for a total of 5 years of follow-up.

Recognizing that our prospectively-enrolled cohort will be subject to selection and referral biases, we also plan to use administrative data maintained by Alberta Health and Alberta Health Services to explore health service use and outcomes in all Albertans with HF. This will be used in two ways:

1. Patients who have provided consent in the prospectively collected cohort will be tracked longitudinally to capture all of their interactions with the healthcare system.

2. Anonymized data obtained from Alberta Health will be used to explore the in-patient, out-patient, emergency department, medications and outcomes of all patients with HF using techniques previously validated by our group $[1,5,42,43]$.

These complementary approaches will allow for appropriate comparisons of patient-, provider- and system-level variables that may vary across the spectrum of HF or those patients at risk for $\mathrm{HF}$.

\section{Sample size}

Alberta HEART plans to recruit 700 patients with up to 100 patients in each of Groups 1, 2 and 5 and 200 patients in each of Groups 3 (HF-PEF) and 4 (known systolic HF). Given the lack of validated data from which to calculate a sample size, a convenience sampling technique has been 
used, recognizing that for some markers (e.g. imaging, exercise, biomarkers) the HEART study will be significantly powered, but for other outcomes (e.g. clinical outcomes) HEART will be underpowered. Nevertheless, the sample size will be increased as appropriate to meet the primary objectives of the study. An additional 100 age- and gendermatched controls (matched to group 3) will be been recruited and tested. Recruitment began in January 2010 and as of March 31st, 2014, 649 participants have been enrolled.

\section{Training program}

Alberta HEART has a training program (Supporting Training Encompassing All in Diastolic Heart Failure [STEADi HF]) to train researchers of all backgrounds and across all 4 pillars of research as described by the Canadian Institutes of Health Research (www.cihr.ca). These competitive training grants are awarded to trainees who are researching an area of heart failure and are collaborating with/mentored by another team member. This will assist in the building of interdisciplinary partnerships along with providing the trainee with a clearer understanding of the research skills in another discipline.

\section{Discovery science}

Of a total of 24 investigators, Alberta HEART includes 8 scientists who have a primary focus on traditional fundamental discovery science. The project also incorporates aspects important for translational science: development of an appropriate animal model from which to test novel therapeutics before first-in-man studies; studying the tissue, cellular and sub-cellular interactions that may be related to a clinical phenotype; and exploring proteomic, metabolomic and genomic pathways to understand overall cardiac function.

\section{Discussion}

Alberta HEART has the primary objective to define new diagnostic criteria for patients with HF-PEF. New criteria will allow for targeted therapies, diagnostic tests and further understanding of the patients, both at-risk for and with heart failure. Interaction across pillars of research and with clinicians, patients, the public and policy makers is embedded within this project to ensure accurate and timely translation of new and existing knowledge for the prevention, diagnosis and treatment of patients with cardiovascular disease.

\section{Abbreviations}

ACC: American College of Cardiology; AHA: American Heart Association; ASE: American Society of Echocardiography; CMR: Cardiac magnetic resonance; COPD: Chronic obstructive pulmonary disease; DEE: Daily energy expenditure; ECG: Electrocardiogram; EF: Ejection fraction; FMD: Flow-mediated dilation; HEART: Heart Failure Etiology and Analysis Research Team; HF: Heart failure; HF-PEF: Heart failure with preserved ejection fraction; HF-PSF: Heart failure with preserved systolic function; LA: Left atrium; LGE: Late gadolinium enhancement;
LV: Left ventricle; LVEF: Left ventricular ejection fraction; MRI: Magnetic resonance imaging; PASP: Pulmonary artery systolic pressure; PAT: Pulse arterial tonometry; QUADAS-2: Quality assessment of diagnostic accuracy studies 2; RV: Right ventricle; SSFP: Steady state free precession; STARD: STAndards for the reporting of diagnostic accuracy studies; STEADi HF: Supporting training encompassing all in diastolic heart failure; TAPSE: Tricuspid annular plane systolic excursion.

\section{Competing interests}

Funding for Alberta HEART is provided by Alberta Innovates - Health Solutions (Grant \# AHFMR ITG 200801018) awarded in 2009. Additional funding is provided by NCE CECR Centre of Excellence for Prevention of Organ Failure and the Alberta Diabetes Institute. In-kind contributions were received from Capital Health Regional Authority (now Alberta Health Services) and the Alberta HEART investigators. JAE, JRBD, FAM, HJD, GDL, GYO and TJA receive salary awards from Al-HS. GYO receives salary awards from HSFC and CIHR. PEL holds the Charles A. Allard Chair in Diabetes Research. FAM holds the University of Alberta Chair in Cardiovascular Outcomes Research. MF holds the Hornstein Chair in Cardiovascular Imaging. HB holds the Heart \& Stroke Foundation Endowed Chair for Cardiovascular Research. TA holds the Merck Frosst Chair in Cardiovascular Research, University of Calgary.

\section{Authors' contributions}

All authors were involved in the conception and design of the research program. TJA, HB, AMC, HJD, JRBD, JAE, MJH, JGH, FAM, GYO, DIP and RBT contributed to the writing of the manuscript. All authors read and approved the final manuscript.

\section{Acknowledgements}

We gratefully acknowledge the patients who have volunteered their time for this study. We also acknowledge the Program Managers (Kelly Narine, PhD, Jennifer Beck, BsAg, MBA, Lisa Tanguay, PhD, Beverly Armstrong, RN, MBA), research coordinators (Marleen Irwin, RRT/C, Lisa Fay, RN, Darlene Ramadan, RN, BN, Leslie Jackson-Carter, RN, BN, CCRP, Andrijana Lawton, RN) and all of the members of Alberta HEART including other Collaborators (Michael Stickland, PhD, Robert Haennel, PhD).

\section{Author details}

'Mazankowski Alberta Heart Institute, 2C2 WMC, 8440-112 Street, Edmonton, AB, Canada. ${ }^{2}$ Libin Cardiovascular Institute of Alberta, Calgary, AB, Canada.

${ }^{3}$ Department of Cardiac Sciences, University of Calgary, Calgary, AB, Canada. ${ }^{4}$ Department of Medicine, University of Alberta, Edmonton, AB, Canada. ${ }^{5}$ Department of Pediatrics, University of Alberta, Edmonton, AB, Canada. ${ }^{6}$ Faculty of Nursing, University of Alberta, Edmonton, $A B$, Canada.

${ }^{7}$ Department of Radiology, University of Calgary, Calgary, AB, Canada. ${ }^{8}$ Departments of Medicine and Radiology, Montreal Heart Institute, Université de Montréal, Montréal, QC, Canada. ${ }^{9}$ Faculty of Rehabilitation Medicine, University of Alberta, Edmonton, AB, Canada. ${ }^{10}$ Department of Physiology, University of Alberta, Edmonton, AB, Canada. ${ }^{11}$ Alberta Diabetes Institute, University of Alberta, Edmonton, $A B$, Canada. ${ }^{12}$ Department of Pharmacology, University of Alberta, Edmonton, AB, Canada. ${ }^{13}$ Department of Radiology and Diagnostic Imaging, University of Alberta, Edmonton, AB, Canada.

${ }^{14}$ Department of Biomedical Engineering, University of Alberta, Edmonton, $A B$, Canada.

Received: 1 May 2014 Accepted: 16 July 2014

Published: 25 July 2014

\section{References}

1. Ezekowitz JA, Kaul P, Bakal JA, Quan H, McAlister FA: Trends in heart failure care: has the incident diagnosis of heart failure shifted from the hospital to the emergency department and outpatient clinics? Eur J Heart Fail 2011, 13:142-147.

2. Johansen H, Strauss B, Arnold JMO, Moe G, Liu P: On the rise: The current and projected future burden of congestive heart failure hospitalization in Canada. Can J Cardiol 2003, 19:430-435.

3. Redfield MM, Jacobsen SJ, Burnett JC Jr, Mahoney DW, Bailey KR, Rodeheffer RJ: Burden of systolic and diastolic ventricular dysfunction in the community. JAMA 2003, 289:194-202. 
4. Bhatia RS, Tu JV, Lee DS, Austin PC, Fang J, Haouzi A, Gong Y, Liu PP: Outcome of heart failure with preserved ejection fraction in a population-based study. N Engl J Med 2006, 355:260-269.

5. Ezekowitz JA, Bakal JA, Kaul P, Westerhout CM, Armstrong PW: Acute heart failure in the emergency department: short and long-term outcomes of elderly patients with heart failure. Eur J Heart Fail 2008, 10:308-314.

6. Stewart AL, Greenfield S, Hays RD, Wells K, Rogers WH, Berry SD, McGlynn EA, Ware JE: Functional status and well-being of patients with chronic conditions. Results from the Medical Outcomes Study. JAMA 1989, 262:907-913.

7. McKelvie RS, Moe GW, Cheung A, Costigan J, Ducharme A, Estrella-Holder E, Ezekowitz JA, Floras J, Giannetti N, Grzeslo A, Harkness K, Heckman GA, Howlett JG, Kouz S, Leblanc K, Mann E, O'Meara E, Rajda M, Rao V, Simon J, Swiggum E, Zieroth S, Arnold JMO, Ashton T, D'Astous M, Dorian P, Haddad H, Isaac DL, Leblanc M-H, Liu P, et al: The 2011 Canadian Cardiovascular Society heart failure management guidelines update: focus on sleep apnea, renal dysfunction, mechanical circulatory support, and palliative care. Can J Cardiol 2011, 27:319-338.

8. Yancy CW, Jessup M, Bozkurt B, Butler J, Casey DE, Drazner MH, Fonarow GC, Geraci SA, HORWICH T, Januzzi JL, Johnson MR, Kasper EK, Levy WC, Masoudi FA, McBride PE, McMurray JJV, Mitchell JE, Peterson PN, Riegel B, Sam F, Stevenson LW, Tang WHW, Tsai EJ, Wilkoff BL, American College of Cardiology Foundation/American Heart Association Task Force on Practice Guidelines: 2013 ACCF/AHA guideline for the management of heart failure: a report of the American College of Cardiology Foundation/ American Heart Association Task Force on practice guidelines. Circulation 2013, 128:e240-e327.

9. Heart Failure Society of America, Lindenfeld J, Albert NM, Boehmer JP, Collins SP, Ezekowitz JA, Givertz MM, Katz SD, Klapholz M, Moser DK, Rogers JG, Starling RC, Stevenson WG, Tang WHW, Teerlink JR, Walsh MN, HFSA: Comprehensive Heart Failure Practice Guideline. J Card Fail 2010, 2010:e1-e194.

10. Ezekowitz JA, Lee DS, Tu JV, Newman AM, McAlister FA: Comparison of One-Year Outcome (Death and Rehospitalization) in Hospitalized Heart Failure Patients With Left Ventricular Ejection Fraction $>50 \%$ Versus Those With Ejection Fraction. Am J Cardiol 2008, 102:79-83.

11. Owan TE, Hodge DO, Herges RM, Jacobsen SJ, Roger VL, Redfield MM: Trends in prevalence and outcome of heart failure with preserved ejection fraction. N Engl J Med 2006, 355:251-259.

12. Authors/Task Force Members, McMurray JJV, Adamopoulos S, Anker SD, Auricchio A, Böhm M, Dickstein K, Falk V, Filippatos G, Fonseca C, Sanchez MAG, Jaarsma T, Køber L, Lip GYH, Maggioni AP, Parkhomenko A, Pieske BM, Popescu BA, Rønnevik PK, Rutten FH, Schwitter J, Seferovic P, Stepinska J, Trindade PT, Voors AA, Zannad F, Zeiher A, ESC Committee for Practice Guidelines (CPG), Bax JJ, Baumgartner $\mathrm{H}$, et al: ESC Guidelines for the diagnosis and treatment of acute and chronic heart failure 2012: The Task Force for the Diagnosis and Treatment of Acute and Chronic Heart Failure 2012 of the European Society of Cardiology. Developed in collaboration with the Heart Failure Association (HFA) of the ESC. Eur Heart J 2012, 33:1787-1847

13. McKelvie RS, Moe GW, Ezekowitz JA, Heckman GA, Costigan J, Ducharme A, Estrella-Holder E, Giannetti N, Grzeslo A, Harkness K, Howlett JG, Kouz S, Leblanc K, Mann E, Nigam A, O'Meara E, Rajda M, Steinhart B, Swiggum E, Le W, Zieroth S, Arnold JMO, Ashton T, D'Astous M, DORIAN P, Haddad H, Isaac DL, Leblanc MH, Liu P, Rao V, et al: The 2012 Canadian Cardiovascular Society Heart Failure Management Guidelines Update: Focus on Acute and Chronic Heart Failure. CJCA 2012,1-14

14. Paulus WJ, Tschöpe C, Sanderson JE, Rusconi C, Flachskampf FA Rademakers FE, Marino P, Smiseth OA, De Keulenaer G, Leite-Moreira AF, Borbély A, Edes I, Handoko ML, Heymans S, Pezzali N, Pieske B, Dickstein K, Fraser AG, Brutsaert DL: How to diagnose diastolic heart failure: a consensus statement on the diagnosis of heart failure with normal left ventricular ejection fraction by the Heart Failure and Echocardiography Associations of the European Society of Cardiology. Eur Heart J 2007, 28:2539-2550.

15. Vasan RS, Levy D: Defining diastolic heart failure: a call for standardized diagnostic criteria. Circulation 2000, 101:2118-2121.

16. Zile MR, Gaasch WH, Carroll JD, Feldman MD, Aurigemma GP, Schaer GL, Ghali JK, Liebson PR: Heart Failure With a Normal Ejection Fraction: Is Measurement of Diastolic Function Necessary to Make the Diagnosis of Diastolic Heart Failure? Circulation 2001, 104:779-782.
17. Massie BM, Carson PE, McMurray JJ, Komajda M, McKelvie R, Zile MR, Anderson S, Donovan M, Iverson E, Staiger C, Ptaszynska A, I-PRESERVE Investigators: Irbesartan in patients with heart failure and preserved ejection fraction. N Engl J Med 2008, 359:2456-2467.

18. Cleland JGF: The perindopril in elderly people with chronic heart failure (PEP-CHF) study. Eur Heart J 2006, 27:2338-2345.

19. Zile MR: New Concepts in Diastolic Dysfunction and Diastolic Heart Failure: Part I: Diagnosis, Prognosis, and Measurements of Diastolic Function. Circulation 2002, 105:1387-1393.

20. Bossuyt PM: Comparative accuracy: assessing new tests against existing diagnostic pathways. BMJ 2006, 332:1089-1092.

21. Sackett DL, Haynes RB: The architecture of diagnostic research. BMJ 2002, 324:539-541.

22. Bossuyt PM, Reitsma JB, Bruns DE, Gatsonis CA, Glasziou PP, Irwig LM, Lijmer JG, Moher D, Rennie D, de Vet HCW, Standards for Reporting of Diagnostic Accuracy: Towards complete and accurate reporting of studies of diagnostic accuracy: the STARD initiative. BMJ 2003, 326:41-44.

23. Whiting PF, Rutjes AWS, Westwood ME, Mallett S, Deeks JJ, Reitsma JB, Leeflang MMG, Sterne JAC, Bossuyt PMM: QUADAS-2 Group: QUADAS-2: a revised tool for the quality assessment of diagnostic accuracy studies. Ann Intern Med 2011, 155:529-536.

24. Zile MR, Baicu CF, Gaasch WH: Diastolic heart failure-abnormalities in active relaxation and passive stiffness of the left ventricle. $N$ Engl J Med 2004, 350:1953-1959.

25. Westermann D, Kasner M, Steendijk P, Spillmann F, Riad A, Weitmann K, Hoffmann W, Poller W, Pauschinger M, Schultheiss H-P, Tschöpe C: Role of left ventricular stiffness in heart failure with normal ejection fraction. Circulation 2008, 117:2051-2060.

26. Hay I, Rich J, Ferber P, Burkhoff D, Maurer MS: Role of impaired myocardial relaxation in the production of elevated left ventricular filling pressure. Am J Physiol Heart Circ Physiol 2005, 288:H1203-H1208.

27. Redfield MM, Jacobsen SJ, Borlaug BA, Rodeheffer RJ, Kass DA: Age- and Gender-Related Ventricular-Vascular Stiffening. Circulation 2005, 112(15):2254-2262.

28. Borlaug BA, Kass DA: Ventricular-vascular interaction in heart failure. Cardiol Clin 2011, 29:447-459.

29. Poole DC, Hirai DM, Copp SW, Musch TI: Muscle oxygen transport and utilization in heart failure: implications for exercise (in)tolerance. Am Physiol Heart Circ Physiol 2012, 302:H1050-H1063.

30. Haykowsky M, Brubaker P, Kitzman D: Role of physical training in heart failure with preserved ejection fraction. Curr Heart Fail Rep 2012, 9:101-106.

31. Agostoni P, Cattadori G, Apostolo A, Contini M, Palermo P, Marenzi G, Wasserman K: Noninvasive Measurement of Cardiac Output During Exercise by Inert Gas Rebreathing Technique: A New Tool for Heart Failure Evaluation. J Am Coll Cardiol 2005, 46:1779-1781.

32. Furchgott RF, Zawadzki JV: The obligatory role of endothelial cells in the relaxation of arterial smooth muscle by acetylcholine. Nature 1980, 288(5789):373-376.

33. Lerman A: Endothelial Function: Cardiac Events. Circulation 2005, 111:363-368

34. Haykowsky MJ, Brubaker PH, Morgan TM, Kritchevsky S, Eggebeen J, Kitzman DW: Impaired Aerobic Capacity and Physical Functional Performance in Older Heart Failure Patients With Preserved Ejection Fraction: Role of Lean Body Mass. J Gerontol A: Biol Med Sci 2013, 68:968-975

35. Kitzman DW, Brubaker PH, Herrington DM, Morgan TM, Stewart KP, Hundley WG, Abdelhamed A, Haykowsky MJ: Effect of Endurance Exercise Training on Endothelial Function and Arterial Stiffness in Older Patients With Heart Failure and Preserved Ejection Fraction: A Randomized, Controlled, Single-Blind Trial. J Am Chem Soc 2013, 62:584-592.

36. Akiyama E, Sugiyama S, Matsuzawa Y, Konishi M, Suzuki H, Nozaki T, Ohba K, Matsubara J, Maeda H, Horibata Y, Sakamoto K, Sugamura K, Yamamuro M, Sumida H, Kaikita K, Iwashita S, Matsui K, Kimura K, Umemura S, Ogawa H: Incremental Prognostic Significance of Peripheral Endothelial Dysfunction in Patients With Heart Failure With Normal Left Ventricular Ejection Fraction. J Am Chem Soc 2012, 60:1778-1786.

37. Anderson TJ, Charbonneau F, Buithieu J, Rose MS: Microvascular Function Predicts Cardiovascular Events in Primary Prevention Long-Term Results From the Firefighters and Their Endothelium (FATE) Study. Circulation 2011, 123(2):163-169.

38. Anderson TJ: Prognostic significance of brachial flow-mediated vasodilation. Circulation 2007, 115(18):2373-2375. 
39. Braunwald E: Biomarkers in Heart Failure. N Eng/ J Med 2008, 358:2148-2159

40. Gerszten RE, Wang TJ: The search for new cardiovascular biomarkers. Nature 2008, 451:949-952.

41. Roach DE, Morck ML, Sheldon RS, Duff HJ: Auto-entrainment risk assessment in heart failure. Circ Arrhythm Electrophysiol 2013, 6:129-136.

42. Kaul P, McAlister FA, Ezekowitz JA, Bakal JA, Curtis LH, Quan H, Knudtson $\mathrm{ML}$, Armstrong PW: Resource use in the last 6 months of life among patients with heart failure in Canada. Arch Intern Med 2011, 171:211-217.

43. Ezekowitz JA, van Walraven C, McAlister FA: Impact of specialist follow-up in outpatients with congestive heart failure. Can Med Assoc J 2005, 172:189-194.

doi:10.1186/1471-2261-14-91

Cite this article as: Ezekowitz et al:: The Alberta Heart Failure Etiology and Analysis Research Team (HEART) study. BMC Cardiovascular Disorders 2014 14:91

\section{Submit your next manuscript to BioMed Central and take full advantage of:}

- Convenient online submission

- Thorough peer review

- No space constraints or color figure charges

- Immediate publication on acceptance

- Inclusion in PubMed, CAS, Scopus and Google Scholar

- Research which is freely available for redistribution 